\title{
Vitrectomy for Diabetic Eye Disease
}

\author{
H. SIGURDSSON, P. S. BAINES and S. T. D. ROXBURGH \\ Dundee
}

\begin{abstract}
Summary
Thirty four eyes which underwent vitrectomy because of diabetic proliferative retinopathy were reviewed.

The overall success rate of the operation was $62 \%$. Excluding table top retinal detachments, which all did badly, the success rate was $72 \%$. Grading by ultrasound was found to be helpful in; (a) planning surgical approach, (b) assessing visual outcome. The most common late complication was cataract. Extracapsular cataract extraction with implantation was found to be successful in these cases.
\end{abstract}

The value of pars plana vitrectomy in the treatment of proliferative diabetic retinopathy complicated by vitreous haemorrhage and traction retinal detachment has been established..$^{1-5}$ Pre-operative factors associated with a poor visual prognosis have been identified. ${ }^{6-9}$ The detection of retinal detachment by ophthalmic ultrasound is of particular importance. ${ }^{10-13}$ We present our experience of vitrectomy for diabetic eye disease and emphasise the usefulness of grading patients by pre-operative ultrasound.

\section{Materials and Methods}

We reviewed retrospectively all diabetic eyes which underwent primary diabetic vitrectomy between November 1983 and May 1986. Thirty one patients were included, three had had bilateral operations, totalling 34 eyes. There were 20 females and 11 males with an average age of 53 years (24-75 years). Sixteen patients had Type I diabetes, the average duration of the disease being 28 years (18-45 years) and fifteen had Type II disease with an average duration of 12 years (2-30 years). (Table I). There were 22 right eyes and 12 left eyes.

Pre-operatively all patients underwent a full ophthalmic assessment with particular reference to visual acuity, relative afferent pupil defect, iris rubeosis, presence of lens opacity, pre-operative laser treatment, intraocular pressure and fundoscopy. The patients were assessed carefully with regard to cardiovascular, renal and neurological complications.

Ultrasound examinations were performed using the Triscan contact Ultrasound $A$ and B scan with $8 \mathrm{MHz}$ transducer with Vector A Scan facility. The B scan determined the anatomical relations of vitreous echoes and membranes to the retina and A scan determined the reflectivity characteristics. Table II lists the criteria used in differentiating retina from vitreous membrane.

The ultrasounds were all recorded on video-tape using a scan convertor and dynamic B scanning during ocular movements was recorded. All but two cf the examinations were carried out by one of the authors (STDR). The ultrasound was graded prognostically into Group 1-4 (Table III) as described by Jalkh et al..$^{10}$ (Fig. 1, a-d).

All surgery was performed by one surgeon (PSB) using common gauge (20 gauge) instruments. After removal of vitreous gel 
Table I

\begin{tabular}{lccc}
\hline Type of DM & No. patients & No. eyes & $\begin{array}{c}\text { Average duration } \\
\text { of DM. (years) }\end{array}$ \\
\hline 1 & 16 & 19 & $28(18-45)$ \\
2 & 15 & 15 & $12(2-30)$ \\
\hline
\end{tabular}

Table II Ultrasonic differentiation of vitreous membranes and retinal detachment

\begin{tabular}{|c|c|c|}
\hline Ultrasound & Retinal detachment & Vitreous membranes \\
\hline \multicolumn{3}{|l|}{ B-scan } \\
\hline Points of attachment & Ora serrata. Optic nerve & Variable \\
\hline Mobility & Mild undulation - rigid & Very mobile - rigid \\
\hline Submembrane space & Echofree & Echoes present \\
\hline \multicolumn{3}{|l|}{ A-scan } \\
\hline Reflectivity & High & Low-medium \\
\hline Quantitative echography & $6-15 \mathrm{~dB}$ & over $20 \mathrm{~dB}$ \\
\hline
\end{tabular}

the fibro-vascular membranes were peeled, segmented or delaminated as felt appropriate. New vessels were cauterised with an endo-probe binolar diathermy all retinal holes were treated with cryotherapy. Endolaser photocoagulation was applied in a standard pattern when this instrument became available. Rhegmatogenous detachments were hydraulically re-attached by simultaneous fluid/gas exchange. Cryotherapy was applied to the post-oral retina in areas of sclerotomies. At the time of surgery the patients were grouped in line with the ultrasound grading. ${ }^{1-4}$

\section{Results}

The follow up period ranged between 4 and 30 months (average 15 months). In 21 eyes $(62 \%)$ the vision improved and in $11(32 \%)$ the vision deteriorated. Analysing the visual outcome in each group revealed an improvement in $86 \%$ of Group 2 patients and $57 \%$ of Group 3 patients. All patients in Group 4 did badly. There were no patients in Group 1, i.e. with complete vitreous detachment, a finding consistent with a previous study. ${ }^{13}$ Visual acuity deteriorated in 11 patients. Two operations were abandoned, one due to uncontrollable haemorrhage, the other due to an inoperable retinal detachment. In Group 2 one patient's eye became phthisical

\section{Table III}

Ultrasound groups

1. Vitreous haemorrhage without vitreous traction

2. Vitreo-retinal adhesion without traction retinal detachment. (V-shape)

3. Traction retinal detachment (focal adhesion, tent-X-shape)

4. Traction retinal detachment (multifocal adhesion, table top H-shaped)

post-operatively. We attribute this to lensectomy, the absence of any pre-operative laser and inadequate operative photocoagulation. The remaining 8 failures are attributable to the development of late retinal detachment, from 2 weeks to 3 months post-operatively. All these patients had flat retina in the immediate post-operative period, seven of these eyes underwent fluid/gas exchange at the time of surgery. Excluding Group 4, i.e. table top traction detachments, the overall success rate was $72 \%$. (Table IV and Scattergram Fig. 2). Figure 3-5 shows how visual acuity changed in each group.

Twenty eyes had pre-operative ultrasound, usually 2 days prior to surgery. In two cases the pre-operative ultrasound detected retinal detachment not noted in a previous 

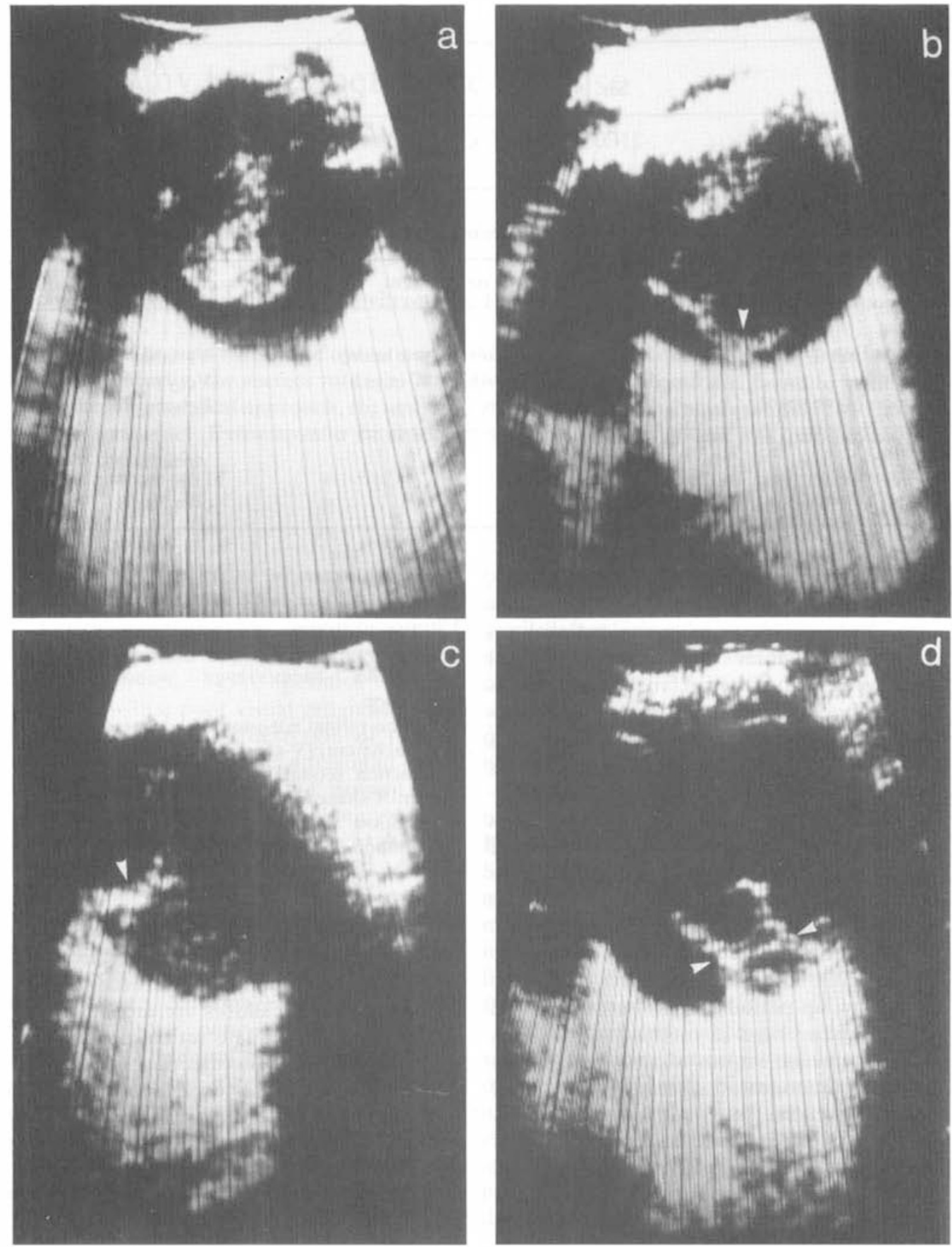

Fig. 1, a-d. Tranverse B-mode images. a. Type 1 classification. Complete posterior vitreous detachment and intragel heamorrhage. Flat retina.

b. Type 2 classification. Incomplete posterior vitreous detachment with focal adhesions. Intragel heamorrhage. Flar retina.

c. Type 3 classification. Posterior vitreous detachment inserting into localised tractional retinal detchment.

d. Type 4 classification. Posterior vitreous detachment inserting into "table top" tractional retinal detachment. 
Table IV Results

\begin{tabular}{ccccc}
\hline Group & $\begin{array}{l}\text { Eyes operated } \\
\text { on }\end{array}$ & $\begin{array}{c}\text { Visual acuity } \\
\text { improved or } \\
\text { the same (eyes) }\end{array}$ & $\begin{array}{c}\text { Visual acuity } \\
\text { worse than } \\
\text { pre-op. (eyes) }\end{array}$ & $\begin{array}{c}\text { Success } \\
\text { rate }(\%)\end{array}$ \\
\hline 2 & 22 & 19 & 3 & 86.3 \\
3 & 7 & 4 & 3 & 57.1 \\
4 & 5 & 0 & 5 & 0 \\
\hline
\end{tabular}

ultrasound examination. Two eyes were wrongly classified when compared to the surgical findings, one should have been in Group 3, the other in Group 4. (Table V).

Three eyes had rubeosis iridis. The vision deteriorated in two following vitrectomy.

Twelve patients had intra-operative endolaser, eight had improved vision post-operatively.

Two eyes with early improvement had to be re-operated because of re-current vitreous haemorrhage. One was a 24 year old male with vitreo-retinal adhesion and a flat retina pre-operatively. A primary procedure which included endo-laser photocoagulation proceeded without complication. $\mathrm{He}$ was a heavy smoker and 3 days post-operatively he developed laryngitis and a severe cough. This resulted in a re-bleed which had not cleared when last seen. The other patient was a 66 year old lady who had a vitrectomy because of Group 2 disease in January 1985. The vision improved for a few months but deteriorated again due to cataract. In January 1986 she had an extra-capsular lens extraction with Sinskey implant following which she developed filamentary keratitis which responded only slowly to topical treatment. She re-bled 2 months following the cataract operation requiring a vitreous cavity washout, following which her visual acuity improved.

Four eyes were aphakic at the time of vitrectomy. Three eyes had lensectomy during the operation and did badly despite two eyes being in Group 2.

Five eyes had extra-capsular lens extraction approximately one year after the primary vitrectomy, one of these had significant lens opacity before the vitrectomy. Four patients had a Sinskey posterior chamber
Table V Accuracy of ultrasound (20 eyes)

\begin{tabular}{lcc}
\hline & $\begin{array}{c}\text { Pre-operative } \\
\text { ultrasound }\end{array}$ & $\begin{array}{c}\text { Operative } \\
\text { findings }\end{array}$ \\
\cline { 2 - 3 } Group 2 & 16 & 14 \\
Group 3 & 3 & 4 \\
Group 4 & 1 & 2 \\
\hline
\end{tabular}

1 missed X-shaped detachments

1 missed $\mathrm{H}$-shaped detachment

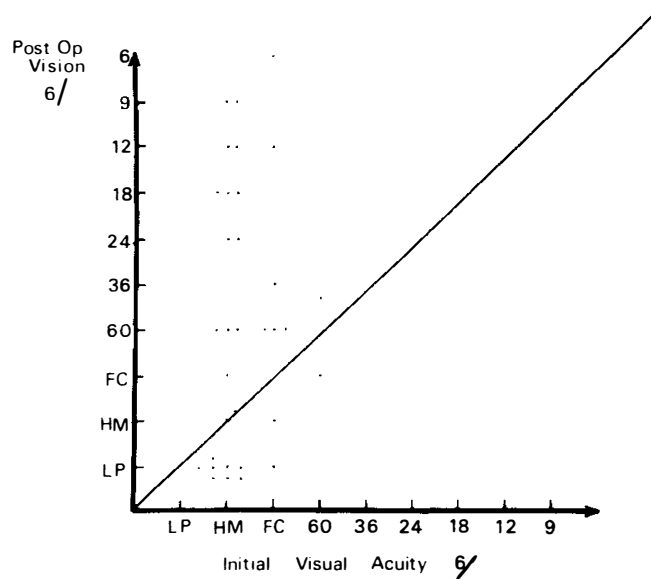

Fig. 2. Scattergram showing visual changes following vitrectomy.

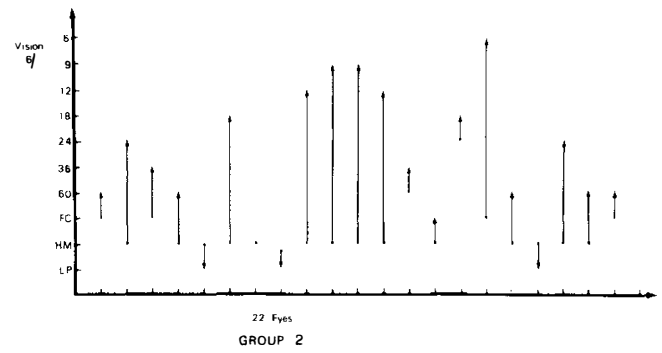

Fig. 3. Visual changes following vitrectomy in Group 2. 
implant, no post-operative problems arose other than the filamentary keratitis described above.

One patient developed aphakic glaucoma and required trabeculectomy. Twenty eyes

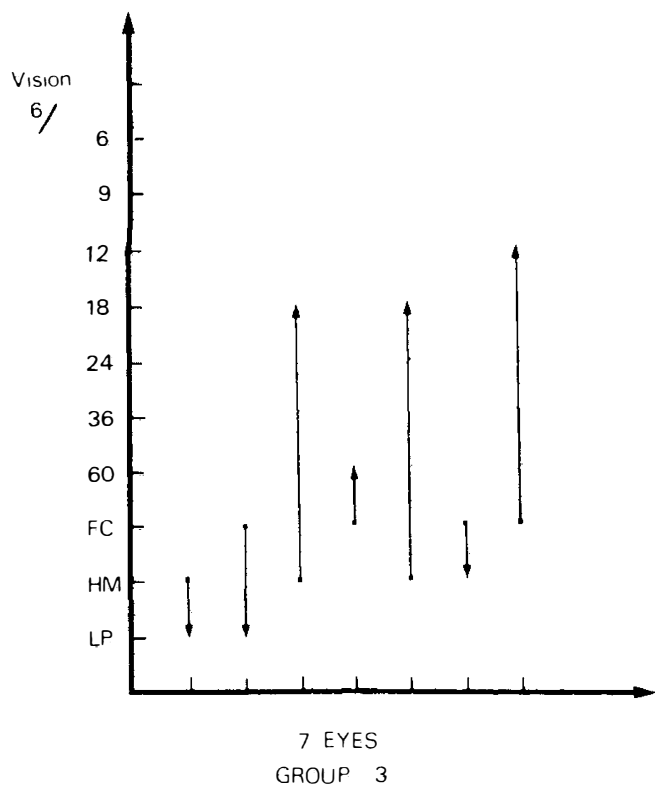

Fig. 4. Visual changes following vitrectomy in Group 3.

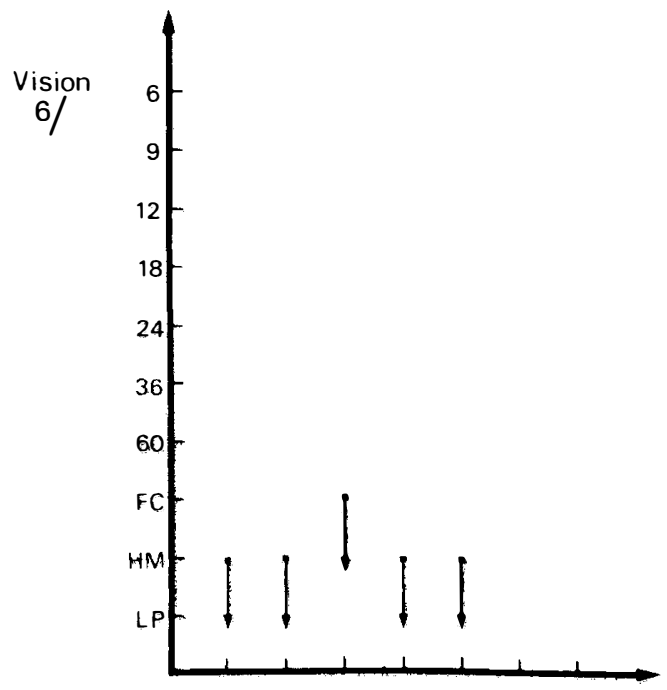

5 EYES

GROUP 4

Fig. 5. Visual changes following vitrectomy in Group.
(59\%) had pre-operative pan-retinal photocoagulation (1000-8000 burns). Fourteen eyes $(41 \%)$ had less than 1000 burns. (Table VI). One patient died one year post-operatively from a myocardial infarction.

\section{Discussion}

Closed intra-ocular micro-surgery for complications of proliferative retinopathy offers hope of restoring useful and stable vision for many patients. From previous studies it is known that patients with vitreous haemorrhage without retinal detachment have the best visual prognosis. ${ }^{1,3,4,14}$ Our findings of $86 \%$ success rate agree with this and it is interesting that 2 of the 3 patients who did badly in this group also had lensectomy, which is recognised as a poor prognostic association. ${ }^{15,16}$

The poor results with table top detachments have previously been commented on. ${ }^{5}$ These patients are the most visually handicapped and therefore the most demanding of surgery despite a poor prognosis. Whether they should be more vigorously dissuaded from surgery is arguable. Excluding this group substantially improves the success rate of this type of surgery.

The pre-operative ultrasound grading used in this study proved to be of great value, not only in allowing a planned surgical approach but also enabling the surgeon to offer the patient a more accurate assessment of visual prognosis. We strongly advocate the use of video-tape recording of the ultrasound as this allowed dynamic features to be reviewed at leisure and discussed with colleagues. We would also like to emphasise the importance of performing ultrasound within days of surgery as these eyes show progressive and changing pathology.

The ultrasound of the two cases where retinal detachment was missed, were reviewed retrospectively. One had a shallow traction

\section{Table VI}

Photocoagulation

Eyes DM $1 \quad$ Eyes DM 2

$<1000$ burns

$>1000$ burns

\begin{tabular}{rr}
4 & 10 \\
15 & 5 \\
\hline
\end{tabular}


detachment at the point of adhesion of a vitreo-retinal membrane. The importance of searching carefully for retinal detachment at areas of vitreo-retinal adhesion has been commented on by previous authors. ${ }^{10,13,17}$

The ultrasound examination of the other case, which belonged to Group 4, was performed by a less experienced examiner. There were extensive vitreo-retinal adhesions with a shallow retinal detachment.

The most significant late complications in our series have been the occurrence of cataract, usually many months post-vitrectomy, and late retinal detachment usually within 3 months. The aetiology of these late retinal detachments is of interest. All exhibited evidence of reparative epiretinal fibrosis, many with obvious secondary retinal breaks, as described previously. ${ }^{18}$ It is our feeling that some of these detachments could have been prevented by silicone oil exchange at the time of initial procedure. The indications for silicone oil in diabetic vitrectomy have not as yet been fully elucidated and are the subject of further study.

In our hands extra-capsular cataract extraction with implantation of a posterior chamber Sinskey style lens had proved very successful and without significant complication.

Despite the proven efficacy of laser photocoagulation in the treatment of proliferative retinopathy, it was disturbing to note the high proportion of patients who had received minimal photocoagulation. It is essential that a continuing programme of education for patients, physicians and ophthalmologists be continued to reduce the incidence of blindness from advanced diabetic eye disease.

We thank Greg Cowper and Angela Ellingford for graphic work and Lynda Rose for typing the manuscripts.

\section{References}

${ }^{1}$ Michels RG, Rice TA, Rice EF: Vitrectomy for diabetic vitreous haemorrhage. Am J Ophthalmol 1983, 95: 12-21.

2 Aaberg TM: Pars plana vitrectomy for diabetic traction retinal detachment. Ophthalmology 1981, 88: 639-42.

${ }^{3}$ Rice TA, Michels RG, Rice EF: Vitrectomy for diabetic traction retinal detachment involving the macula. A.J.O. 1983, 95: 22-33.
${ }^{4}$ Machemer R and Blankenship GW: Vitrectomy for proliferative diabetic retinopathy associated with vitreous haemorrhage. Ophthalmology 1981, 88: 643-46.

5 McLeod D, Lever PK, Feretis E: Vitrectomy for severe diabetic eye disease. Trans Ophthalmol Soc UK 1980, 100: 291-8.

${ }^{6}$ Blankenship GW: Pre-operative prognostic factors in diabetic pars plana vitrectomy. Ophthalmology 1982, 89: 1246-49.

7 Jalkh A, Takahashi M, Topilow HW, Trempe CL, McMeel JW: Prognostic value of vitreous findings in diabetic retinopathy. Arch Ophthalmol 1982, 100: 432-4.

8 Thomson JT, Auer CL, Bustros SD, Michels RG, Rice TA, Glaser BM: Prognostic indicators of success and failure in vitrectomy for diabetic retinopathy. Ophthalmology 1986, 93: 290-4.

${ }^{9}$ Scherfig E, Edmund J, Tinning S, Krough E: Prognostic parameters in pars plana vitrectomy. Acta Ophthalmol 1983, 61: 788805 .

10 Jalkh AE, Avila MP, El-Markabi H, Trempe CL, Schepens CL: Immersion A and B-Scan Ultrasonography. Arch. Ophthalmol 1984, 102: 686-90.

11 Jerneld B, Algvere P, Singh G: An ultrasonograohic study of diabetic vitreoretinal disease with low visual acuity. Acta Ophthalmol 1980, 58: 193-201.

12 Blumenkranz and Byrne SF: Standardised achography (ultrasonography) for the detection and characterisation of retinal detachment. Ophthalmol 1982, 89: 821-31.

${ }^{13}$ McLeod D and Restori M: Ultrasonic examination in severe diabetic eye disease. $\mathrm{Br}$ J Ophthalmol 1979, 63: 533-8.

14 Rice TA, Michels RG, Rice EF: Vitrectomy for diabetic rhegmatogenous retinal detachment. Am J Opthalmol 1983, 95: 34-44.

15 Rice TA, Michels RG, Maguire MG, Rice EF: The effect of lensectomy on the incidence of iris neovascularisation and neovascular glaucoma after vitrectomy for diabetic retinopathy. Am J Ophthalmol 1983, 95: 1-11.

16 Blankenship GW: The lens influence on diabetic vitrectomy results. Arch Ophthalmol 1980, 98: 2196-8.

17 Fuller DG and Hutton WL: Pre-surgical evaluation of eyes with opaque media. Grune and Stratton, New York 1982, page 125-126.

${ }^{18}$ Barry BJ, Hiscott PS, Grierson I, Marshall J, McLeod D. Reparative Epiretinal Fibrosis After Diabetic Vitrectomy. Trans Ophthalmol Soc UK 1985, 104: 285-. 